\title{
In situ zirconia: a superior reinforcing filler for high performance nitrile rubber composites
}

\author{
Shubham C. Ambilkar, ${ }^{1}$ Naresh D. Bansod, ${ }^{1}$ Bharat P. Kapgate,${ }^{2}$ Amit Das, ${ }^{3}$ Petr Formanek ${ }^{3}$, \\ Kasilingam Rajkumar ${ }^{2}$ Chayan Das, ${ }^{1 *}$ \\ ${ }^{1}$ Department of Chemistry, Visvesvaraya National Institute of Technology, Nagpur, India \\ ${ }^{2}$ Indian Rubber Manufacturers Research Association, Thane, India \\ ${ }^{3}$ Leibniz-Institut für Polymerforschnug Dresden e.V., Dresden, Germany
}




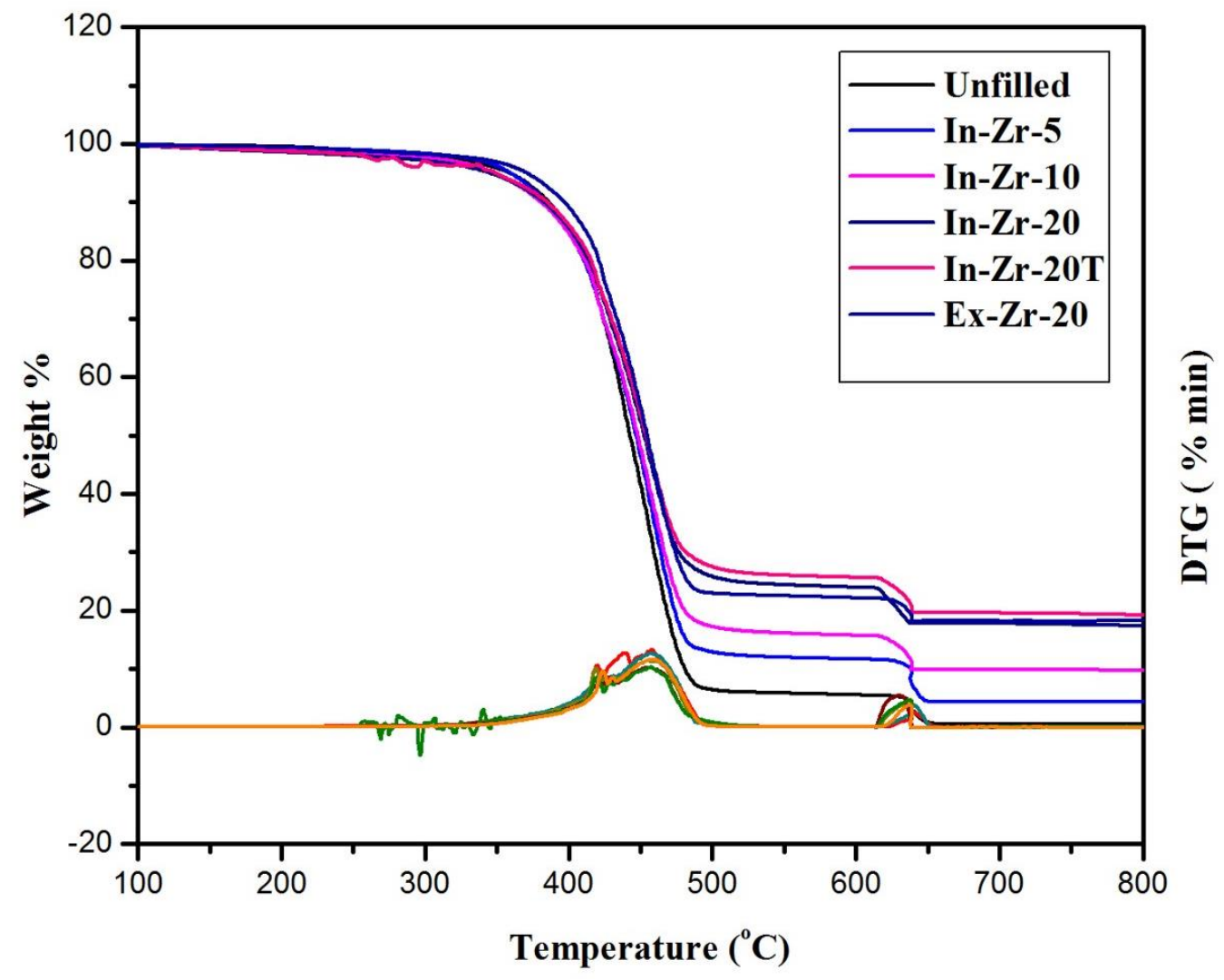

Figure S1:Thermo gravimetric curves of the unfilled and zirconia filled composites. 